Journal of Power Sources, Vol.170, issue 2, July 2007, pp.376-386.

\title{
Water distribution measurement for a PEMFC through
}

\section{neutron radiography}

Yong-Song Chen ${ }^{\mathrm{a}}$, Huei Peng ${ }^{\mathrm{a} *}$, Daniel S. Hussey ${ }^{\mathrm{b}}$, David L. Jacobson ${ }^{\mathrm{b}}$, Doanh T. Tran ${ }^{\mathrm{c}}$, Tarek Abdel-Baset ${ }^{\mathrm{c}}$, Mark Biernacki ${ }^{\mathrm{c}}$

${ }^{a}$ Department of Mechanical Engineering, University of Michigan, Ann Arbor, 1231 Beal Avenue, Ann Arbor, MI 48109-2121, USA

${ }^{\mathrm{b}}$ Center for Neutron Research, National Institute of Standards and Technology, 100 Bureau Dr., Stop 8461, Gaithersburg, MD 20899-8461, USA

${ }^{\mathrm{c}}$ DaimlerChrysler Corporation, 800 Chrysler Drive, Auburn Hills, MI 48326-2757, USA

*Corresponding author. Tel.: +1 734 936-0352; fax: +1 734 764-4256

E-mail Address: hpeng@umich.edu 
Journal of Power Sources, Vol.170, issue 2, July 2007, pp.376-386.

\begin{abstract}
Neutron radiography has been used for in-situ and non-destructive visualization and measurement technique for liquid water in a working proton exchange membrane fuel cell (PEMFC). In an attempt to differentiate water distribution in the anode side from that in the cathode side, a specially designed cell was machined and used for the experiment. The major difference between our design and traditional flow field design is the fact the anode channels and cathode channels were shifted by a channel width, so that the anode and cathode channels do not overlap in the majority of the active areas.

The neutron radiography experiments were performed at selected relative humidities, and stoichiometry values of cathode inlet. At each operating condition, the water distribution in anode/cathode gas diffusion layers (GDLs) was obtained. Image processing with four different spatial masks were applied to those images to differentiate liquid water in four different types of areas. Results indicate that the reactant gas relative humidity and stoichiometry significantly influence current density distribution and water distribution.
\end{abstract}

Keywords: PEMFC; Water visualization; Water Management; Neutron Radiography 
Journal of Power Sources, Vol.170, issue 2, July 2007, pp.376-386.

\section{Introduction}

Effective water management increases performance and durability of the proton exchange membrane fuel cells (PEMFCs). The membrane in PEMFCs must be sufficiently hydrated because its conductivity relies primarily on the humidity state of the membrane. The water quantity inside the PEMFC is influenced by two major factors. The first factor is the vapor content at the inlet reactants, which can be manipulated to a certain extent by using external humidifiers. The second and more influential source is the water generation by the chemical reaction in a PEMFC. Since water is generated as a by-product when the fuel cell is generating power, this water source can be said to be a "disturbance" to any water management system, which is trying to maintain proper humidity level without flooding. Since water is generated throughout the active area, the downstream area can be flooded even when the upstream area is under-saturated. This creates a challenging environment for water management, which adversely affects the efficiency and reliability in the operation of the PEMFCs,

Measuring water content inside conducting PEMFCs is nontrivial because these experiments need specially designed fuel cells and/or instrumentations. Several research groups have proposed different water metrology methods. Mench et al. [1] used gas chromatography to measure the in-situ water vapor distribution in an operating fuel cell, which directly maps water distribution in the anode and cathode of an operating fuel cell. Nishikawa et al. [2] used a relative humidity ( $\mathrm{RH}$ ) sensor to measure at six locations along the air flow field. Nishikawa's results, however, only showed water vapor distribution and not liquid water content. These results may not be very relevant since in a conducting fuel 
Journal of Power Sources, Vol.170, issue 2, July 2007, pp.376-386.

cell, part of the membrane has to be in an over-saturated condition, while part of it will likely to be severely under-saturated. Tüber et al. [3] designed a transparent fuel cell with double straight flow channels and a cathode covered with plexiglass. In their experiments, the images of water formed inside the air flow channels were recorded by a digital camera. However, quantifying the amount of water in the channels is not straightforward, and the optical methods cannot measure the liquid water content in the GDL.

Another method of observing water distribution is through neutron radiography. Mosdale et al. [4] used small-angle neutron scattering (SANS) technique to determine the water profile across the membrane direction of a running PEMFC in the late 1990's. The spectra resulting from these techniques were characterized by the presence of a maximum scattering called "ionomer peak" and of an intense scattering at very low angles. The ionomer peak was related to the existence of water pools in the membrane. With SANS, the water content in a membrane was observed. Bellows et al. [5] used neutron radiography to measure water transport profiles across membrane in a working fuel cell. The cell in these experiments had a membrane thickness of $500 \mu \mathrm{m}$, which enabled visualizing the through-plane water profile across the membrane. Bellows' results showed that the water content in the membrane varied with operating condition, but no significant water gradient across the membrane was observed. Using the same neutron facility, Satija et al. [6] demonstrated the use of neutron radiography to observe water distribution inside the fuel cell. A four-cell commercial stack was used in their study; the image-masking technique was used to isolate water formation in the anode channels, the cathode channels, and the gas diffusion layer (GDL). However, due to the multi-cell stack and overlap of anode 
Journal of Power Sources, Vol.170, issue 2, July 2007, pp.376-386.

channels and cathode channels, it was not easy to differentiate water on the anode side from that in the cathode side.

Kramer et al. [7, 8] applied statistical methods, including interpretation of the probability density function of the relative neutron transmission, to quantify the liquid water volume in an operating PEMFC and a direct methanol fuel cell (DMFC) and to compare serpentine and interdigitated flow field designs. Pekula et al. [9] used a facility at the Pennsylvania State University to obtain neutron images. Liquid droplets were observed in the final two-thirds of the flow field at higher current densities, and mostly in the corners. The liquid droplet velocity was not constant due to interactions with the channel walls and other droplets. Recently, Chuang et al. [10] determined the water content in the fuel cell by using a pre-calculated look-up table that correlates water thickness to pixel luminance. This is perhaps the first paper to give a detailed quantitative description of the water distribution in a way that can be compared with model calculations. Chuang et al. quantified liquid water content in the GDL and flow channels of PEMFCs under flooded and non flooded conditions. According to their results, a few tenths of a milligram of liquid water in the active area is enough to affect the fuel cell performance. Ludlow et al. [11] also used neutron radiography to quantify the liquid water within an operating fuel cell under various gas flow conditions.

A common element of the fuel cells used in these studies is each had identical and overlapped anode and cathode flow fields, making it impossible to distinguish water content in the anode and in the cathode during measurement. Knowing where liquid water accumulates with more certainty helps to understand the water transport in a PEMFC. In 
Journal of Power Sources, Vol.170, issue 2, July 2007, pp.376-386.

addition, since the final goal of our study is to use the experimental results to build a model suitable for prediction, prevention and control of liquid water inside a fuel cell, we need to design a cell that can help us to visualize water distribution more clearly and accurately.

In this study, the flow field of a cell was designed for the purpose of differentiating anode and cathode under neutron imaging. The effect of cathode inlet stoichiometry values and $\mathrm{RH}$ were investigated by using the neutron radiography. The liquid water within the cell was then quantified into specific regions by using an image masking technique.

\section{Experimental method}

\subsection{Fuel cell design}

A single cell with an active area of $100 \mathrm{~cm}^{2}$ was used in this experiment. The membrane electrode assembly (MEA) was provided by Umicore [12]. It has a membrane

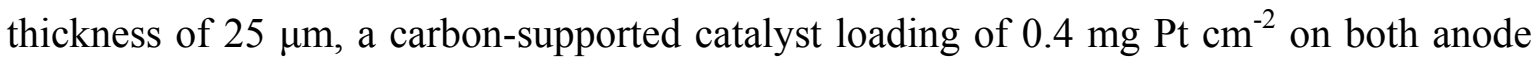
and cathode, and gas diffusion layers (GDLs). The GDLs are made of carbon papers with an uncompressed thickness of $230 \mu \mathrm{m}$.

The flow field plates are made of graphite. Because commercial graphite plates have porosity that could trap water-which will interfere with the neutron imaging, the graphite plates were densified with resin before machining. The anode flow field is a 6channel serpentine design, whereas the cathode flow field is a straight parallel design, as shown in Fig. 1 (a) and (b). The channel depth, width and rib width are 1.0, 1.6, and 1.7 $\mathrm{mm}$, respectively. In order to differentiate anode flow channels from cathode flow channels 
Journal of Power Sources, Vol.170, issue 2, July 2007, pp.376-386.

in the neutron radiography experiment, the flow fields of anode and cathode were shifted to minimize overlap, as shown in Fig. 1 (c). This flow field design was expected to provide more useful results.

The current collectors are made of gold-plated copper plates. End plates are made of aluminum alloy, used to compress MEAs, flow field plates and current collectors precisely. The cell assembly is compressed by using twelve bolts with nuts.

\subsection{Neutron image acquisition and test condition}

All the experiments were performed at Beam Tube 2 (BT-2) of the Center for Neutron Research (NCNR), a research center of the National Institute of Standards and Technology (NIST). The experimental setup is depicted in Fig. 2. The NCNR facility was already discussed in the literature [13]. High energy neutrons (MeV) were created by fission in the reactor core and were moderated to thermal energies $(\mathrm{meV})$ by $\mathrm{D}_{2} \mathrm{O}$. The remaining gamma and high energy neutron contribution of the beam was filtered out by a $15 \mathrm{~cm}$ thick single crystal bismuth filter that is very transmissive to thermal neutrons when cooled to $77 \mathrm{~K}$ by liquid nitrogen. The filtered beam was then collimated with a simple thermal neutron pinhole (made from boron and cadmium) located directly downstream from the filter. In this study, a $2 \mathrm{~cm}$ aperture produced an effective $\mathrm{L} / \mathrm{d}$ ratio of 300 and a neutron fluence rate of $1.7 \times 10^{7} \mathrm{~cm}^{-2} \mathrm{~s}^{-1}$. The images were acquired with a $\mathrm{Li}^{6}-$ doped $\mathrm{ZnS}$ scintillator placed directly in contact with an amorphous silicon flat panel detector which has a pixel pitch of $0.127 \mathrm{~mm}$ and a spatial resolution of about $0.250 \mathrm{~mm}$ at a frame rate of $1 \mathrm{~Hz}$. 
Journal of Power Sources, Vol.170, issue 2, July 2007, pp.376-386.

The fuel cell was controlled by a fuel-cell test station that was custom-built for NIST. This test stand provides accurate flows of humidified hydrogen and air as well as dry nitrogen and pure/nitrogen mixed oxygen. A heat tape wrapped around the perimeter of the cell heated the cell to a temperature of $70{ }^{\circ} \mathrm{C}$. The cell was purged with dry nitrogen and dry air for at least 15 mins prior to taking dry reference images. To reduce image noise, a series of 1000 images of the dry cell was taken and averaged to obtain the reference image. The water content in the fuel cell is then calculated based on the difference between the test image and the reference image.

The effect of cathode reactant humidity and stoichiometry were investigated in this study. The cell was operated at different current densities, $0,0.1,0.2,0.3,0.4,0.5,0.6,0.7$ $\mathrm{A}-\mathrm{cm}^{-2}$. For each current density, the test was conducted at 2 relative humidity values, $50 \%$ and $100 \%$, and 3 stoichiometry values, 2, 3, and 4 for the cathode inlet. The anode gas was not humidified and the stoichiometry was 1.2 for all experiments, except that a minimum flow rate for both cathode and anode was set at levels corresponding to $0.2 \mathrm{~A} \mathrm{~cm}^{-2}$. Neutron imaging was initiated at least 5 mins after a new condition was established.

\subsection{Image analysis}

After the raw images were captured, the water content in the cell was extracted by analyzing the image data using code developed at NIST. Ten images were used to obtain averaged test data to reduce noise. The image intensity of each pixel of the image reflects the recorded neutron intensity, which quantifies the amount of liquid water at that spatial location. Once the quantity and location of liquid water along the flow-channel direction is 
Journal of Power Sources, Vol.170, issue 2, July 2007, pp.376-386.

determined, the focus shifts to further understanding where liquid water forms along the through-MEA direction. It is well known that the PEM is quite thin and hydrophilic; therefore the water content in it typically remains relatively constant and does not influence the observed water quantity in a neutron image. In an earlier study [14], where an un-shifted flow field design was used, the water content "under channel" was found to be much less than that "under ribs," and the amount of water under channel does not change significantly with current density. The under-saturated test conditions reported in another study [15] showed similar results. These earlier results imply that the liquid water has a tendency to accumulate in the GDLs under ribs, and the quantity can vary significantly. Water that is present in the channels, on the other hand, is carried through the flow channel and its quantity is relatively fixed. The above two papers both used fuel cells with a small active area and straight flow channels. Therefore, the water distribution within the active area is quite uniform. Since the anode flow field was identical to the cathode flow field in their designs, the area that was identified by the neutron image to have liquid water under channel is at locations where anode channels and cathode channels overlap (referred to as "Ch-Ch"), whereas the area under ribs is at locations where anode ribs and cathode ribs overlap ("Rib-Rib").

In the present study, since the flow fields of anode and cathode are not identical and are shifted spatially, there are two additional combinations. The two additional types of areas, which in fact accounts for the majority of the active area, were the overlap of cathode channels and anode ribs (which we will call An_rib), and that of anode channels and cathode ribs (Ca_rib), as shown in Fig. 3. To quantify liquid water in the four different 
Journal of Power Sources, Vol.170, issue 2, July 2007, pp.376-386.

areas, image masking techniques were used to determine the location of water inside the cell. Image masking refers to the process in which all neutron intensity in an image is blocked except for pixels that lie within a specified region. Four masks were created to quantify liquid water in the four different areas, as shown in Fig. 4. Another important consideration is that active area was not small enough to be regarded as uniform, so the active area was divided into fifteen segments along the anode flow field, as shown in Fig. 5, which is numbered successively along the anode flow direction. The average liquid water thickness was then calculated for each mask in each of the fifteen segments. The quantification result is the average thickness for each segment, for the four different types of area. The water thickness in the plots cannot be interpreted as the thickness of liquid water accumulated in any specific layer because the equivalent water thickness of each layer in MEA is unknown.

\section{Results and discussion}

The calculated average liquid water quantity can be used for qualitative and quantitative assessment. The water quantity can be used for the calibration and validation of a mathematical model. In addition, we can also use it as a visualization tool, through colorizing the neutron density images. Fig. 6 shows a colorized neutron image. The bottom half of the image, which corresponds to the downstream anode flow, contains more water than the top half. However, it is not possible to distinguish from this image whether the water accumulation is located in the membrane, anode/cathode channels, or anode/cathode 
Journal of Power Sources, Vol.170, issue 2, July 2007, pp.376-386.

GDLs. By applying the masking technique described earlier, however, we will be able to identify the location of liquid water more accurately.

\subsection{Anode and cathode differentiation}

First, we will show that the flow field design and image processing technique developed in this study help in differentiating liquid water in the anode and in the cathode. Fig. 7 shows the average water thickness in the 15 segments as a function of current density by using Rib-Rib (a), Ch-Ch (b), Ca_rib (c), and An_rib (d) masks, when the cathode inlet $\mathrm{RH}$ is fixed at $50 \%$. Fig. 8 shows the results when the cathode inlet air is fully humidified. The layout of the subplot matrix corresponds to the segment distribution in Fig. 5. In the middle columns of Fig. 7 (a)-(b) and Fig. 8 (a)-(b), the plots show nothing, because there are no $\mathrm{Ch}-\mathrm{Ch}$ and Rib-Rib areas in those segments. In Figs. 7 (a) and 8 (a), which show results for application of the Rib-Rib mask, a maximum water thickness of approximately $100 \mu \mathrm{m}$ was observed in segment 15 . Since segment 15 is the last one along the anode flow field, it is reasonable for it to contain the most liquid water. The results imply that the maximum amount of liquid water that can accumulate in the Rib-Rib area is equivalent to the water thickness of around $100 \mu \mathrm{m}$. So when we observe water thickness in excess of $100 \mu \mathrm{m}$, it is very likely the amount over $100 \mu \mathrm{m}$ is due to liquid water in the channels.

The water thickness in Fig. 7 (d) was observed to decrease slightly with increasing current density. This phenomenon becomes more pronounced when the cathode inlet gas was fully humidified, as is displayed in Fig. 8 (d). The water thickness in Fig. 8 (d) 
Journal of Power Sources, Vol.170, issue 2, July 2007, pp.376-386.

decreases to approximately 20-80 $\mu \mathrm{m}$, depending on the segment position. Figs 8 (a) and (b) show that the water thickness in the Rib-Rib and Ch-Ch areas of segments 1, 6, 7, 12, and 13 does not significantly change with current density. However, the water thickness in the Ca_rib and An_rib areas of these segments decreases with current density, as shown in Figs 8 (c) and (d). This result suggests the decrease in $\mathrm{Ca} \_$rib and $\mathrm{An} \_$rib areas is due to the water content in the GDLs under the ribs. This trend was also observed in the operating conditions with fully humidified or over-humidified inlet gas reported by Turhan et al. [15]. This phenomenon is perhaps related to water transport by electro-osmotic drag from anode

to cathode, which is highly related to current density [16]. Another possible explanation of this phenomenon is the changing flow rate. At fixed stoichiometric value, the gas flow rate varies proportionally with current density. Since in this study only the cathode gas is humidified and the anode gas is dry, water in the anode GDL has the tendency to move into the channels through convective mass transfer. Therefore, high flow rate, resulting from high current density, reduces the total amount of water measured in the neutron image. Both explanations seem to be plausible and in fact could co-exist.

\subsection{Effect of cathode inlet stoichiometry}

Three different cathode inlet stoichiometry values were tested to study the impact of flow rate on water quantity and distribution. In Figs. 7 and 8, it is observed that at high current densities, experiments at a low stoichiometry value of 2 result in noticeably higher water content in the GDLs. This is because when the gas flow rate is low, less water is taken away, resulting in more water accumulation in the GDLs. This phenomenon is more 
Journal of Power Sources, Vol.170, issue 2, July 2007, pp.376-386.

significant when the cathode inlet RH is low. Fig. 9 shows the water content in the An_rib area and $\mathrm{Ca}$ _rib area along the anode flow channel when the cathode inlet $\mathrm{RH}$ is $50 \%$. The numbers in the abscissa denote segment number. At the low stoichiometry value of 2 , a significant amount of water thickness in those areas was observed. However, the segments near the inlet do not have much liquid water. Starting from segment number 8 or 9 , the water thickness increases toward a maximum of about $120 \mu \mathrm{m}$.

When the stoichiometry value is higher at 3 or 4 , the water thicknesses vary from 0 to approximate $15 \mu \mathrm{m}$ along the anode flow field. These values do not change significantly with current density. Liu's work [17] showed that when inlet RH is low, the upstream segments have lower current densities. Lower current density is accompanied by weaker electro-osmotic drag from anode to cathode and less water generation in the cathode. Therefore, the cathode side could be under-saturated, which contributes to higher resistivity and lower current density. Fig. 10 shows a similar trend when cathode inlet RH was $100 \%$. In addition, the water profile along the anode flow channel seems to be similar for all stoichiometric values. In Fig. 10 (a), it can be seen that at low current densities of 0.1 to $0.3 \mathrm{~A} \mathrm{~cm}^{-2}$, the amount of liquid water starts to increase from segment 3 , whereas at high current densities, it starts to increase from segment 7. In Schneider's study [18], both distributed current densities and water content were measured and the results support similar trends to this work. Schneider found similar profile for current density distribution and water content distribution, followed a similar profile. The trend indicates that current density distribution is more even under low load than under high load. 
Journal of Power Sources, Vol.170, issue 2, July 2007, pp.376-386.

At each current density, the cell voltage was recorded as the main indicator of cell performance. Fig. 11 compares polarization curves obtained while different stoichiometry values of cathode inlet gas were fed to the cell under two different RH conditions. Regardless of the value of RH, lower cathode stoichiometry appears to result in lower performance. When the stoichiometry is 2 , the polarization curve does not seem to be sensitive to cathode inlet RH despite the fact that the water content in the GDL is quite different. This implies that at low stoichiometry, water accumulation in the GDL is not correlated to low performance. For current densities between 0.1 and $0.5 \mathrm{~A} \mathrm{~cm}^{-2}$, which are in the ohmic polarization region, it is very likely the low performance is due to low membrane water content instead of flooding. At lower cathode flow rate, little water is carried to the membrane, which causes low membrane hydration and low membrane conductivity. Therefore, cell performance is low even when the cathode inlet gas is fully humidified.

\subsection{Effect of cathode inlet relative humidity}

The effect of reactant relative humidity $(\mathrm{RH})$ on the water accumulation in the GDLs is investigated in this study at two different RH levels: $50 \%$ and $100 \%$. The effect of cathode inlet RH can be studied by comparing Figs. 9 and 10. When the cathode inlet gas is $50 \%$ (thus under-saturated), it takes water from the GDL through convective mass transfer [19]. When under-saturated cathode gas with stoichiometry of 3 or 4 is fed to the cell, the water thickness in the Ca_rib area is approximately $20 \mu \mathrm{m}$; however, the water thickness is apparently larger at low stoichiometry of 2 . If a fully saturated cathode gas is 
Journal of Power Sources, Vol.170, issue 2, July 2007, pp.376-386.

fed to the fuel cell, the water content in the area increases and stoichiometry value has little effect on the water content. From Fig. 10 (b), the water content profiles in the last several segments seem to be fully developed. The maximum water thickness in the Ca_rib area is approximately $120 \mu \mathrm{m}$, which could be the maximum amount of water that can accumulate in the GDL under those operating conditions. Since the GDL cannot hold any more water, once the water is generated in the cathode catalyst layer, the water is expelled from the hydrophobic GDL into the channels. If the flow field design can not remove liquid water effectively, flooding will occur.

Since the anode gas is not humidified in this study, the only way for the anode side to acquire water is through the back diffusion mechanism, which carries water from the cathode to the anode. Water transport by back diffusion not only counter-balances the electro-osmotic drag from anode to cathode, but also compensates for the water loss in the GDL caused by dry flowing anode gas. Because of the lower gas flow rate in the anode, the water content in the anode GDL under the rib is not necessarily lower, and sometimes could actually be higher than that in the cathode GDL, as can be seen by comparing Fig. 10 (a) and 10 (b). This is because the higher gas flow rate could prevent a large quantity of water from accumulating in the cathode side. At high current densities, however, the anode GDL generally contains less water than the cathode GDL because the electroosmotic drag becomes more significant and more liquid water transports from anode to cathode.

The polarization curves in Fig. 11 show that under the same stoichiometry, the cell has lower performance when the cathode inlet RH is low. This is likely due to insufficient 
Journal of Power Sources, Vol.170, issue 2, July 2007, pp.376-386.

water in the inlet air to humidify the membrane from the cathode side. In Fig. 11 (b), the cell voltages were unstable at the operating condition of $0.7 \mathrm{~A} \mathrm{~cm}^{-2}$ for all three stoichiometry values. It is possible that; because the cathode is fully saturated, the unstable voltages are caused by flooding in the cathode GDL, especially for those segments near the outlet.

As a final note, the cell voltage measured in our experiment seems to be lower than values reported in typical fuel cell papers. Although we have not yet been able to pinpoint the root cause, there are at least two possible explanations. First, since the flow channel is shifted to improve visualization, it might have unintentional adverse effects on the gas diffusion in the GDL, for example, due to the "cross bite" of the ribs of the graphite plates. It is also possible that even though we used the compression ratio suggested by Umicore, the suggested value is optimized for "regular" cell designs instead of our cross-bite design. Since the focus of this paper is on water distribution rather than cell performance, the low cell voltage could be a concern, but not a flaw.

These experiments, in combination with our specially designed flow fields and image processing technique, provide a new way to investigate liquid water distribution in anode and cathode. The results show the effects of relative humidity and stoichiometry of cathode inlet on water accumulation as well as cell performance. These new results still provide some interesting insight to the field of fuel cell water management, prediction, and control-which is the current focus of our research.

\section{Conclusions}


Journal of Power Sources, Vol.170, issue 2, July 2007, pp.376-386.

Neutron radiography is a valuable method to detect and quantify liquid water inside an operating fuel cell. The Neutron facility at the NCNR is able to provide images with high spatial-resolution that are useful for the investigation of the water distribution for operating PEMFCs. In this study, the influences of cathode stoichiometry and RH on liquid water accumulation and distribution were investigated. Experiments were conducted for three different stoichiometries and two relative humidity values for the cathode inlet. In order to differentiate anode channels and cathode channels in the neutron images, a fuel cell with a shifted flow field design was used. The shifted flow field design resulted in four types of channel/rib combinations, anode channel/cathode channel, anode rib/cathode rib, anode channel/cathode rib, and cathode channel/anode rib. By using image masking techniques, the water content was quantified in four areas. In addition, the water content distribution within the cell was also studied; the cell was divided into fifteen segments along the direction of anode reactant flow. The test results thus can be used for model validation of 2D fuel cell models.

The results showed the effect of cathode inlet RH and stoichiometry on liquid water accumulation and distribution. It was observed that under fully humidified conditions, the water content at anode GDL decreased with increasing current densities. The water content profile fully developed at the segment near the outlet. In addition, at under-saturated operating condition and lower stoichiometry value of 2, a significant amount of water content in GDLs was observed. In contrast, at higher stoichiometry values, the water content is lower. We also observed that current densities distributed more evenly at the operating conditions of high stoichiometry value and high relative humidity. 
Journal of Power Sources, Vol.170, issue 2, July 2007, pp.376-386.

\section{Acknowledgement}

The first two authors would like to acknowledge the support from National Science Foundation (NSF0408664) for their research at the University of Michigan. The authors

also would like to express their gratitude to Dr. B.J. Weng of the Chung-Shan Institute of Science and Technology, Taiwan, for manufacturing the fuel cell components, and Mr. Rob Privette of Umicore for providing the membrane electrode assemblies.

In addition we acknowledge that this work was supported by the U.S. Department of Commerce, the NIST Ionizing Radiation Division, the Director's office of NIST the NIST Center for Neutron Research, the NIST Center for Neutron Research and the Department of Energy through interagency agreement no. DE-AI01-01EE50660.

\section{References}

[1] M.M. Mench, Q.L. Dong, C.Y. Wang, J. Power Sources, 124 (2003) 90-98.

[2] H. Nishikawa, R. Kurihara, S. Sukemori, T. Sugawara, H. Kobayasi, S. Abe, T. Aoki, Y. Ogami, A. Matsunaga, J. Power Sources, 155 ( 2006) 213-218.

[3] K. Tüber, D. Pócza, C. Hebling, J. Power Sources, 124 (2005) 403-414.

[4] R. Mosdale, G. Gebel, M. Pineri, J. Membrane Science, 118 (1996) 269-277.

[5] R.J. Bellows, M.Y. Lin, M. Arif, A.K. Thompson, D. Jacobson. J. Electrochem. Soc., 146 (1999) 1099-1103.

[6] R. Satija, D.L. Jacobson, M. Arif, S.A. Werner, J. Power Sources, 129 (2004) 238-245. 
Journal of Power Sources, Vol.170, issue 2, July 2007, pp.376-386.

[7] D. Kramer, J. Zhang, R. Shimoi, E. Lehmann, A. Wokaun, K. Shinohara, G.G. Scherer, Electrochim. Acta, 50 (2005) 2603-2614.

[8] D. Kramer, E. Lehmann, G. Frei, P. Vontobel, A. Wokaun, G.G. Scherer, Nuclear Instruments and Methods in Physics Research, A 542 (2005) 52-60.

[9] N. Pekula, K. Heller, P.A. Chuang, A. Turhan, M.M. Mench, J.S. Brenizer, K. Ünlü, Nuclear Instruments and Methods in Physics Research, A 542 (2005) 134-141.

[10] P.A. Chuang, A. Turhan, A.K. Heller, J.S. Brenizer, T.A. Trabold, M.M. Mench, Proceedings of FUELCELL, 2005.

[11] D.J. Ludlow, C.M. Calebrese, S.H. Yu, C.S. Dannehy, D.L. Jacobson, D.S. Hussey, M. Arif, M.K. Jensen, G.A. Eisman, J. Power Sources 162 (2006) 271-278.

[12] Certain trade names and company products are mentioned in the text or identified in an illustration in order to adequately specify the experimental procedure and equipment used. In no case does such identification imply recommendation or endorsement by the National Institute of Standards and Technology, nor does it imply that the products are necessarily the best available for the purpose.

[13] D.S. Hussey, D.L. Jacobson, M. Arif, P.R. Huffman, R.E. Williams, J.C. Cook, Nuclear Instruments and Methods in Physics Research A 542 (2005) 9-15.

[14] J. Zhang, D. Kramer, R. Shimoi, Y. Ono, E. Lehmann, A. Wokaun, K. Shinohara, G.G. Scherer, Electrochim. Acta, 51 (2006) 2715-2727.

[15] A. Turhan, K. Heller, J.S. Brenizer, M.M. Mench, J. Power Sources, 160 (2006) 1195-1203. 
Journal of Power Sources, Vol.170, issue 2, July 2007, pp.376-386.

[16] T.A. Zawodzinski, J. Davey, J. Valerio, S. Gottesfeld, Electrochim. Acta, 40 (1995) 297-302.

[17] Z. Liu, Z. Mao, B. Wu, L. Wang, V. M. Schmidt, J. Power Sources, 141 (2005) 205210.

[18] I.A. Schneider, D. Kramer, A. Wokaun, G.G. Scherer, Electrochemistry Communications, 7 (2005) 1393-1397.

[19] Z.H. Wang, C.Y. Wang, K.S. Chen, J. Power Sources, 94 (2001) 40-50. 
Journal of Power Sources, Vol.170, issue 2, July 2007, pp.376-386.

\section{Figure Captions}

Fig. 1. Flow field design of (a) anode; (b) cathode. (c) shifted flow fields. (details of inlet and outlet are not shown)

Fig. 2. Experimental setup at NIST Center of Neutron Research.

Fig. 3. Schematic of four kinds of channel/rib combinations and water accumulation.

Fig. 4. Four masks used to quantify liquid water in (a) Rib-Rib; (b) Ch-Ch; (c) Ca_rib; (d) An_rib.

Fig. 5. Schematic of 15 segments along anode flow field.

Fig. 6. Colorized neutron image presents the liquid water distribution.

Fig. 7. Water distribution within the cell in the area of (a) Rib-Rib; (b) Ch-Ch; (c) Ca_rib;

(d) An_rib when the cathode inlet relative humidity is 50\%. (The numbers inside subplots indicate the segment number)

Fig. 8. Water distribution within the cell in the area of (a) Rib-Rib; (b) Ch-Ch; (c) Ca_rib; (d) An_rib when the cathode inlet relative humidity is $100 \%$. (The numbers inside subplots indicate the segment number) 
Journal of Power Sources, Vol.170, issue 2, July 2007, pp.376-386.

Fig. 9. Water distribution along anode flow filed by using (a) An_rib mask; (b) Ca_rib mask, when cathode inlet relative humidity is $50 \%$.

Fig. 10. Water distribution along anode flow filed by using (a) An_rib mask; (b) Ca_rib mask, when cathode inlet relative humidity is $100 \%$.

Fig. 11. Polarization curves when cathode inlet relative humidity is (a) $50 \%$; (b) $100 \%$. 
Journal of Power Sources, Vol.170, issue 2, July 2007, pp.376-386.

\section{Figures}

(a)

(b)
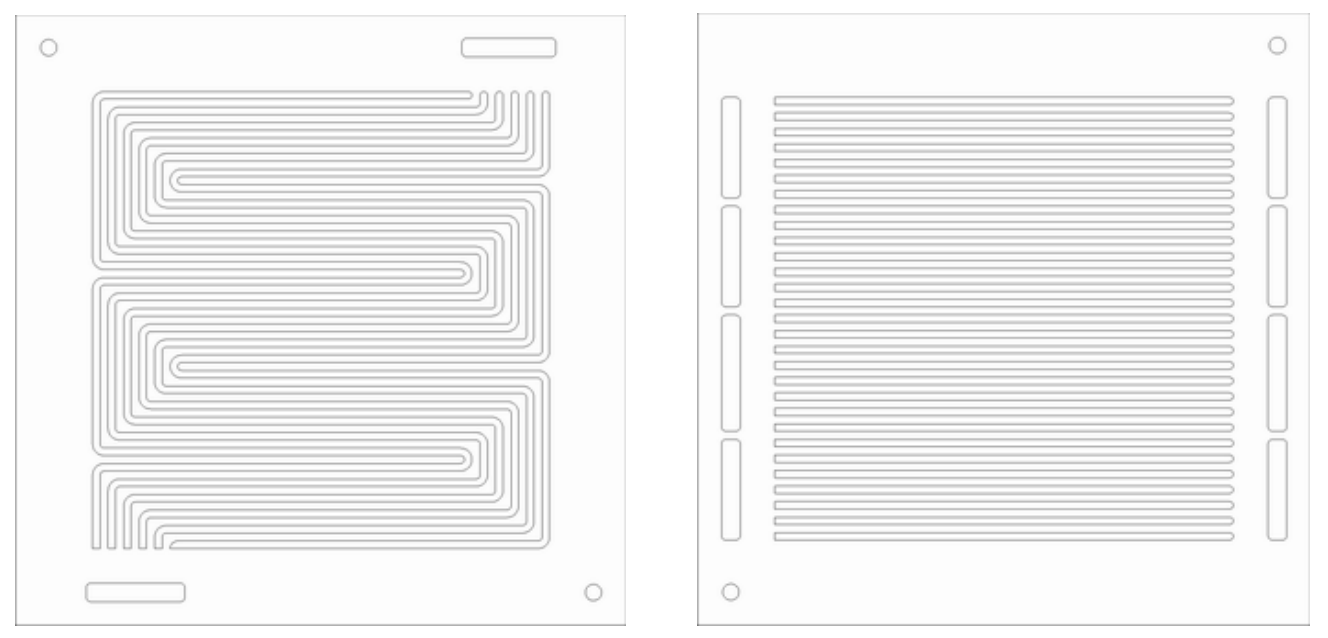

(c)

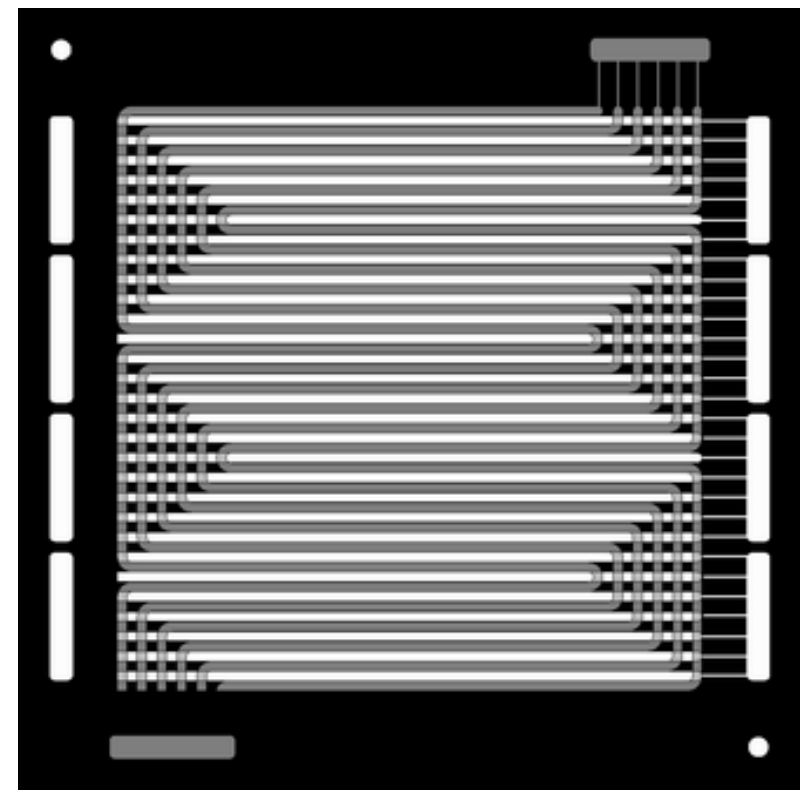

Fig. 1 
Journal of Power Sources, Vol.170, issue 2, July 2007, pp.376-386.

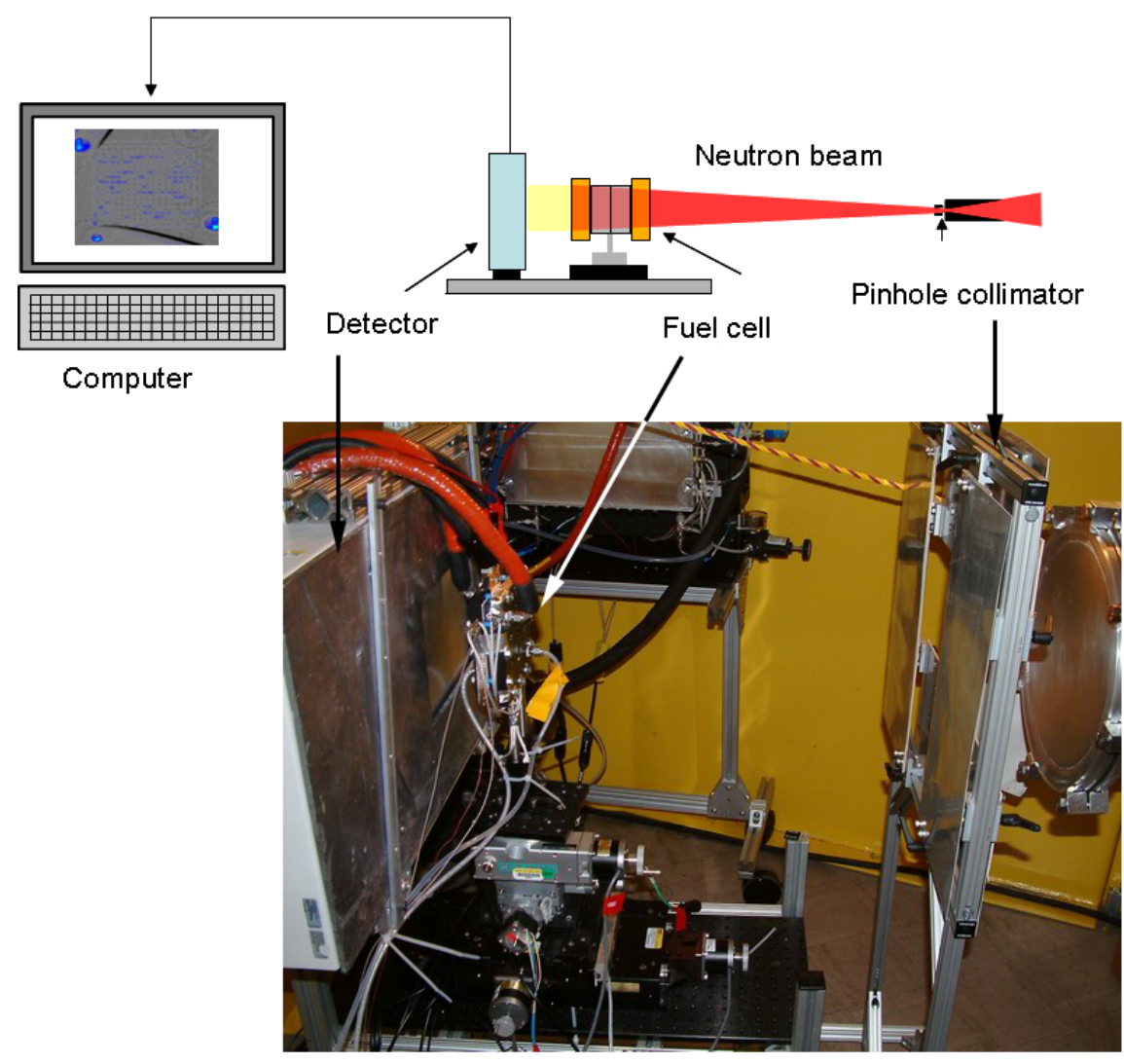

Fig. 2

Beam direction
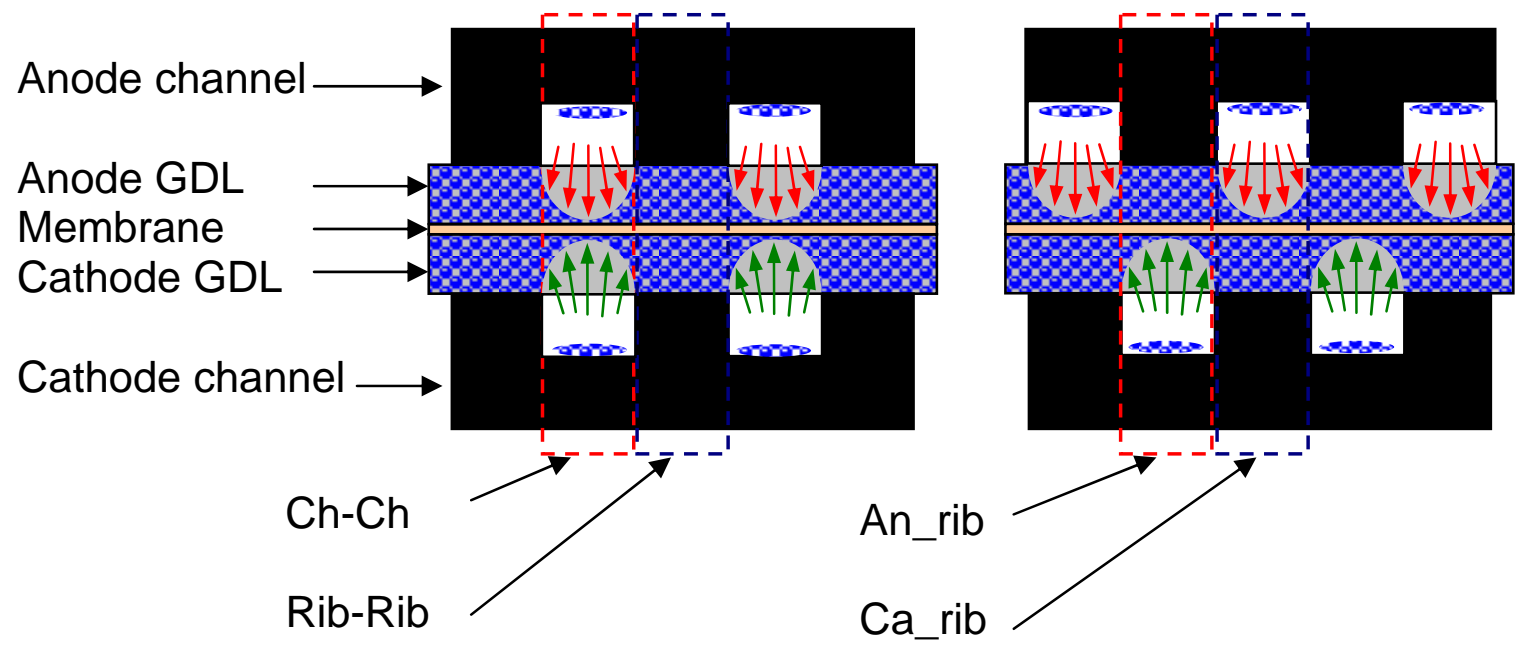

Fig. 3 
(a)

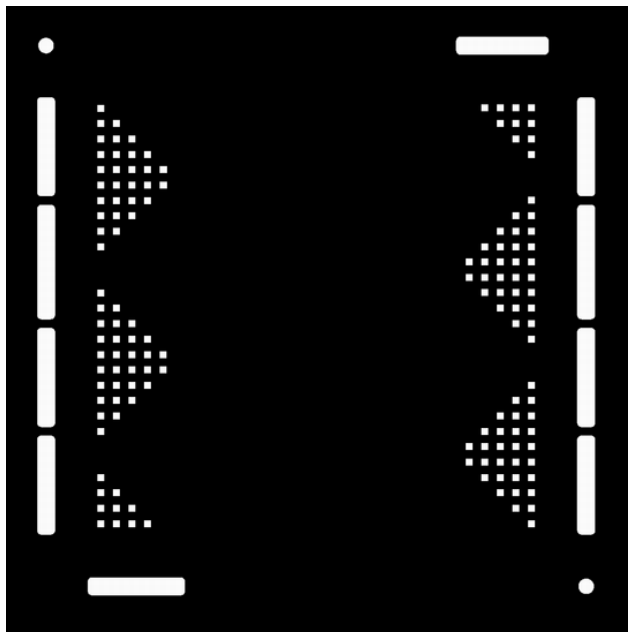

(c)

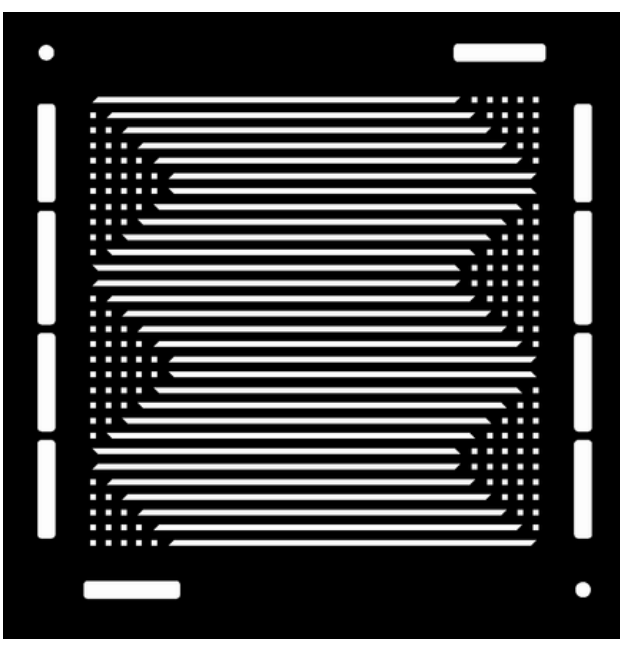

(d)

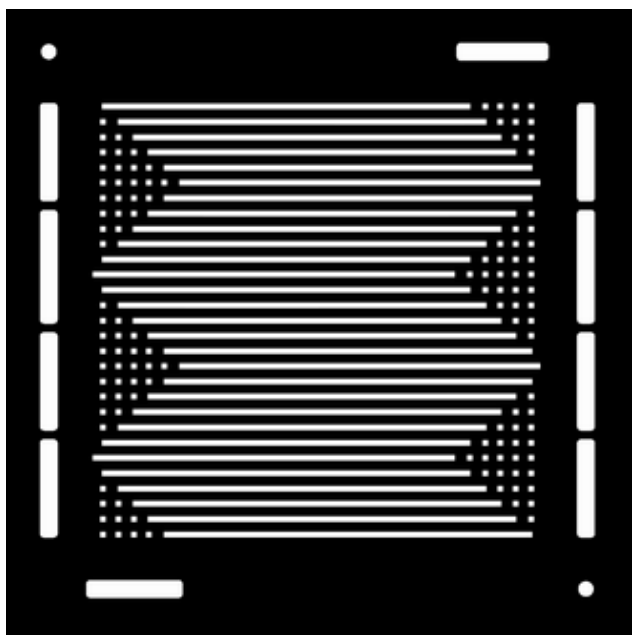

(b)

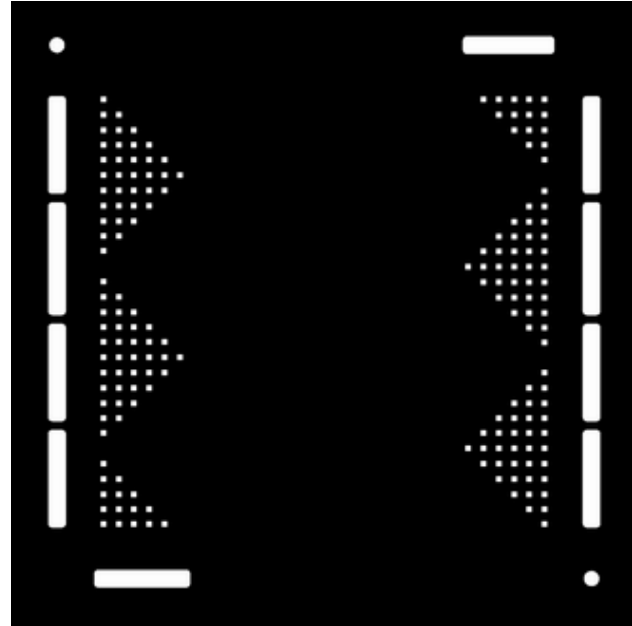

Fig. 4 
Journal of Power Sources, Vol.170, issue 2, July 2007, pp.376-386.

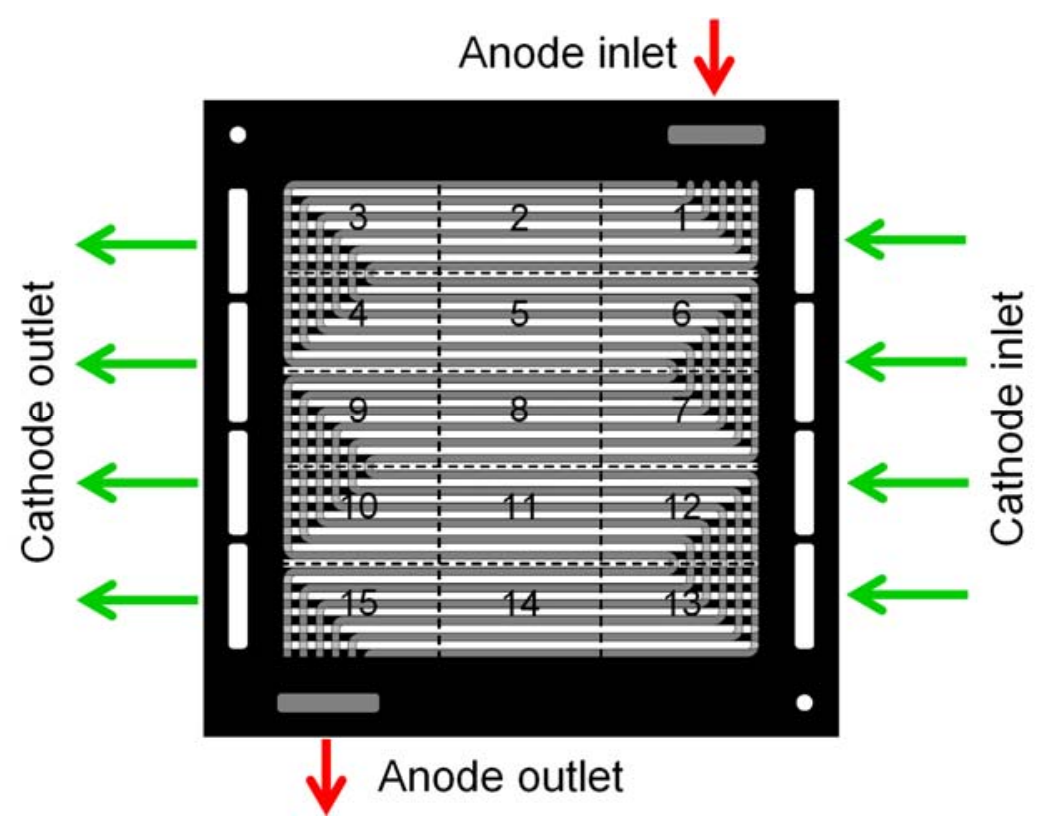

Fig. 5
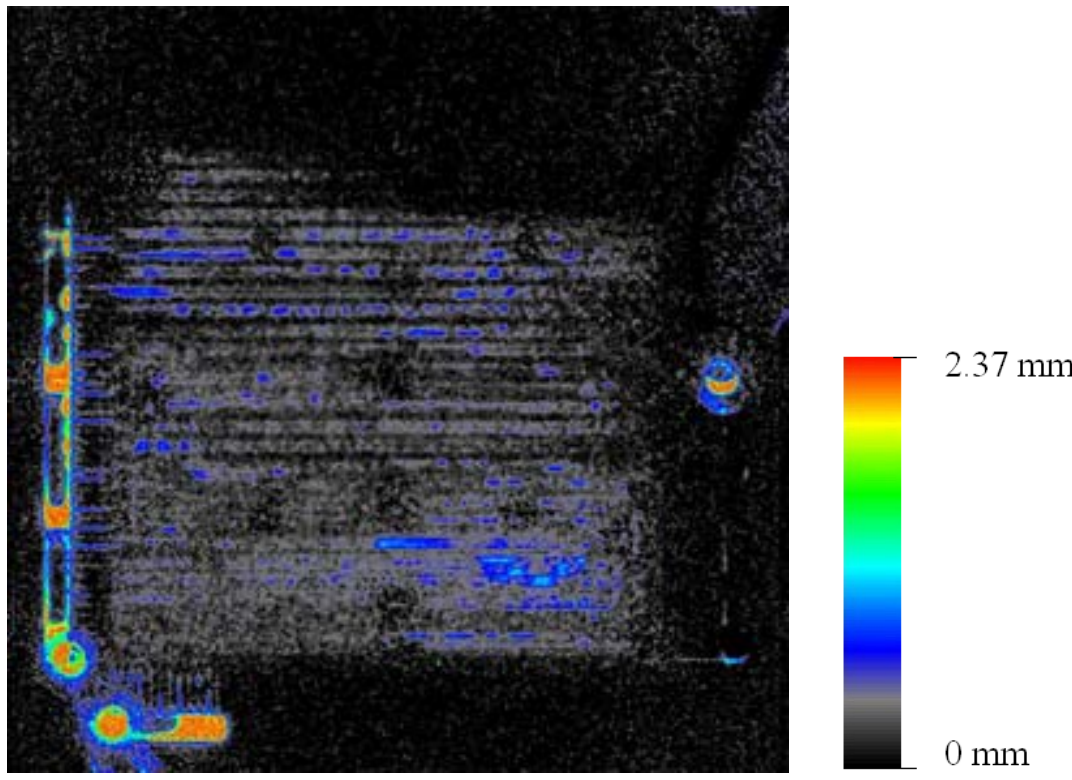

Fig. 6 
(a)

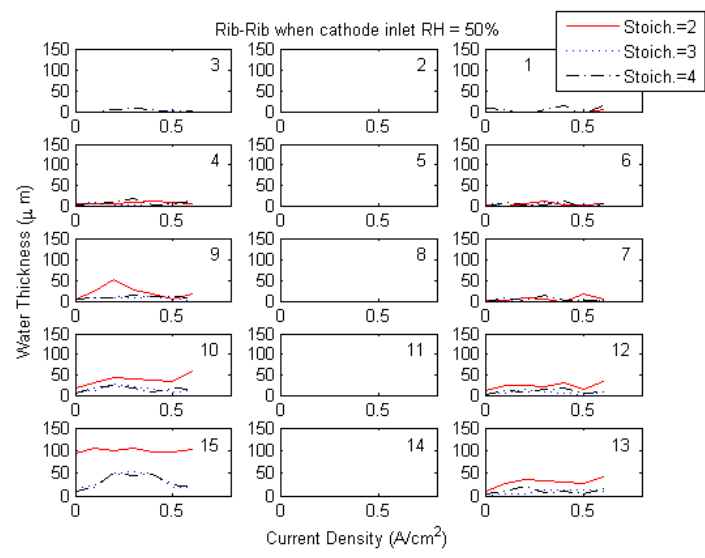

(c)

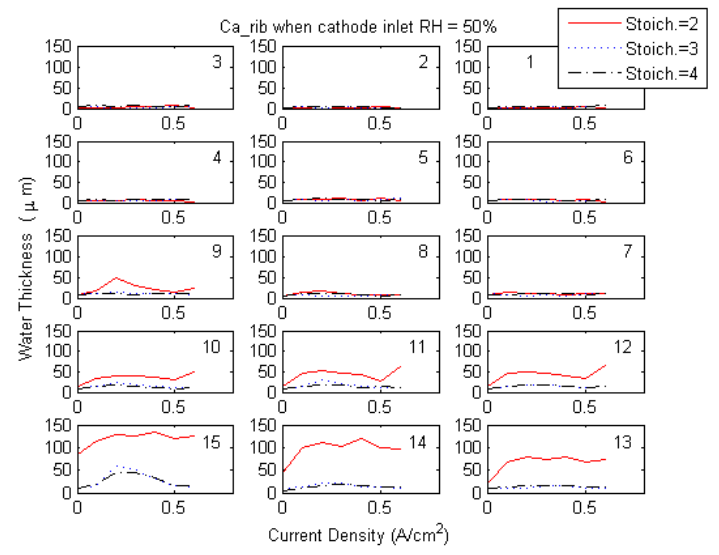

(b)

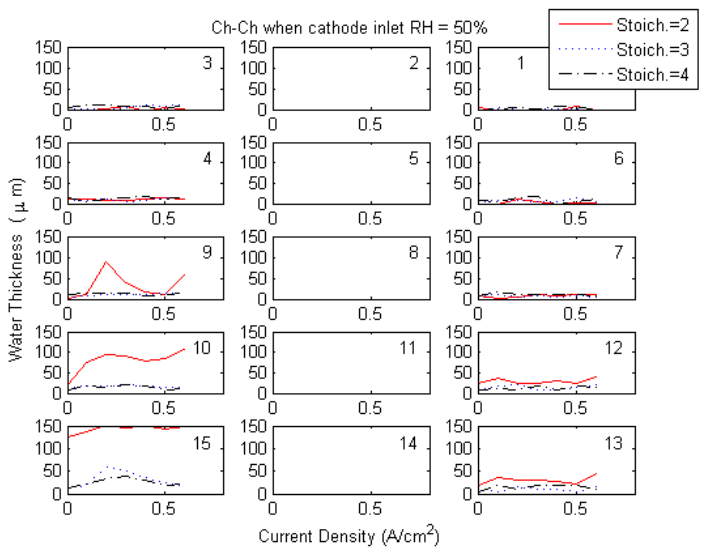

(d)

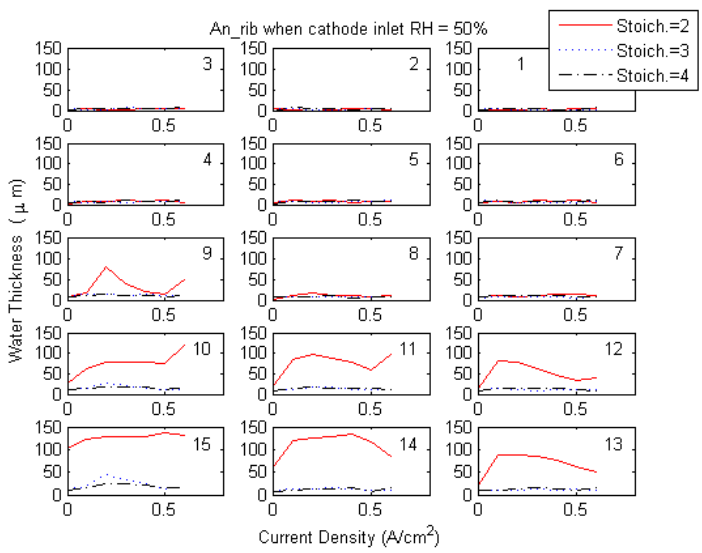

Fig. 7 
(a)

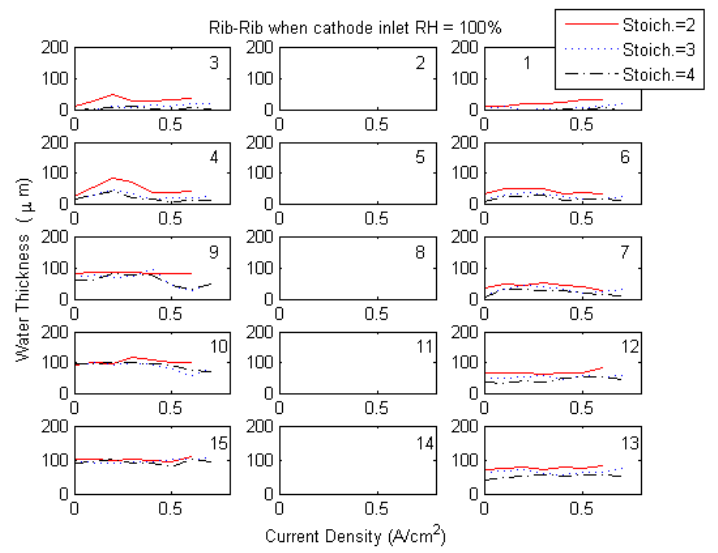

(c)

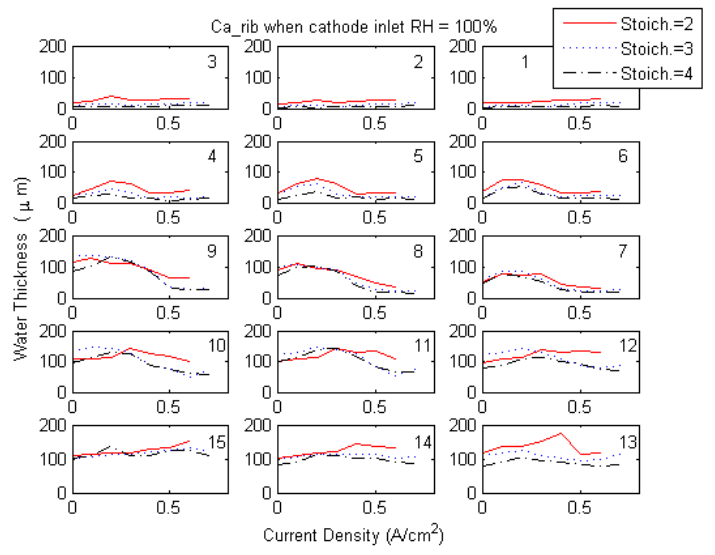

Fig. 8 (b)

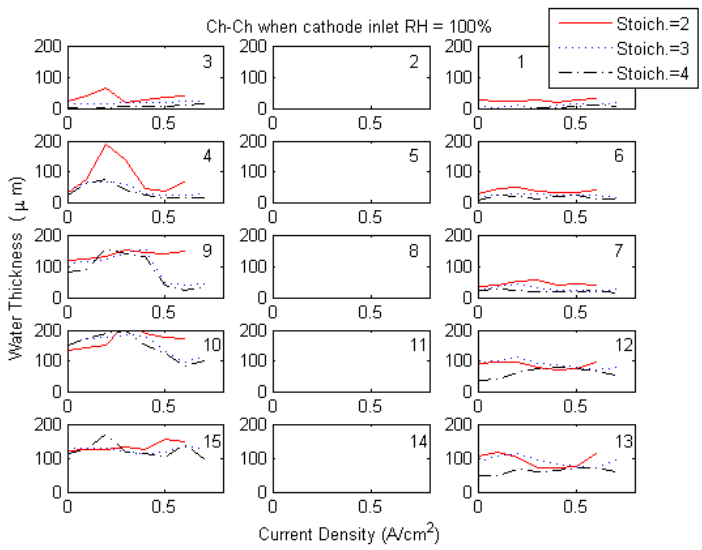

(d)

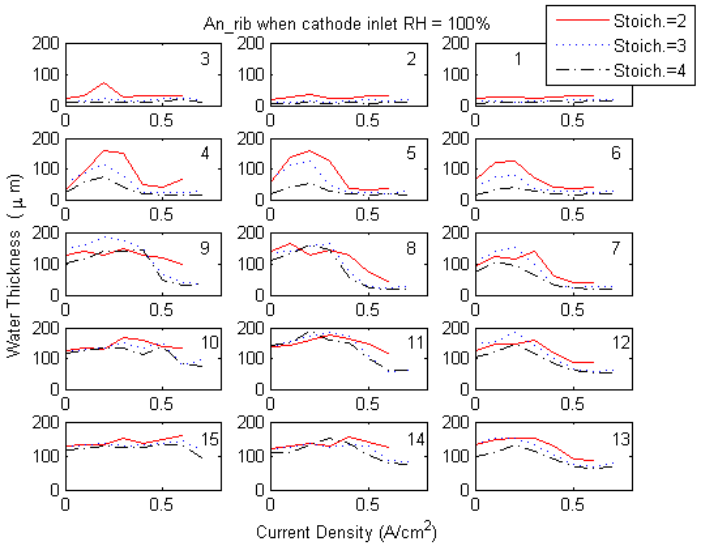


Journal of Power Sources, Vol.170, issue 2, July 2007, pp.376-386.

(a)
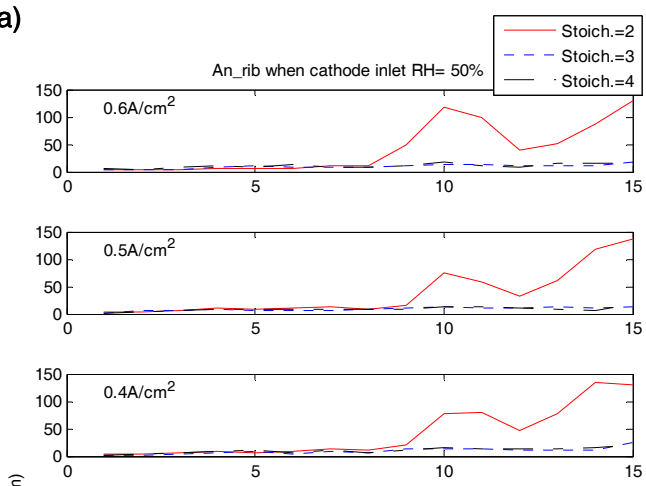

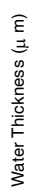
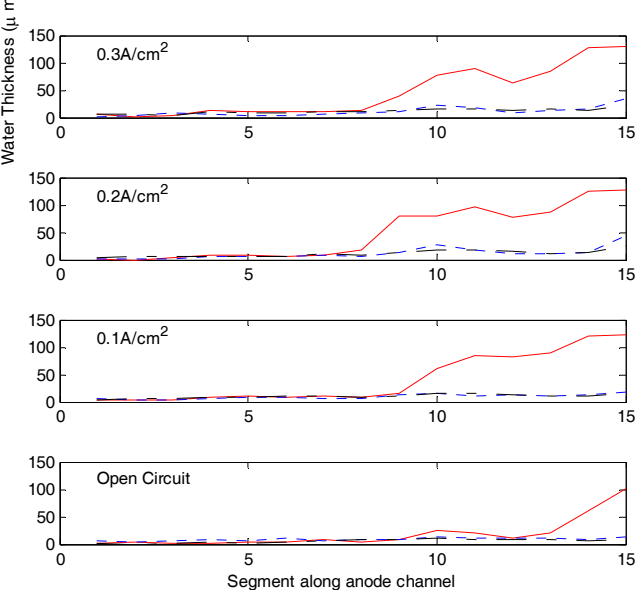

(b)
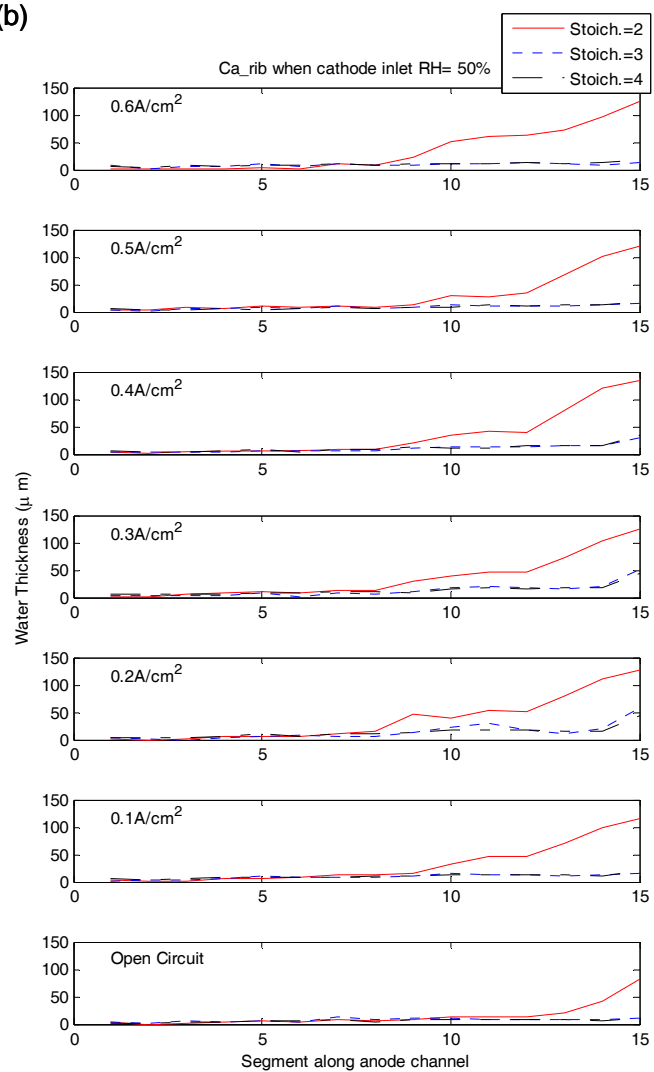

Fig. 9 
Journal of Power Sources, Vol.170, issue 2, July 2007, pp.376-386.

(a)
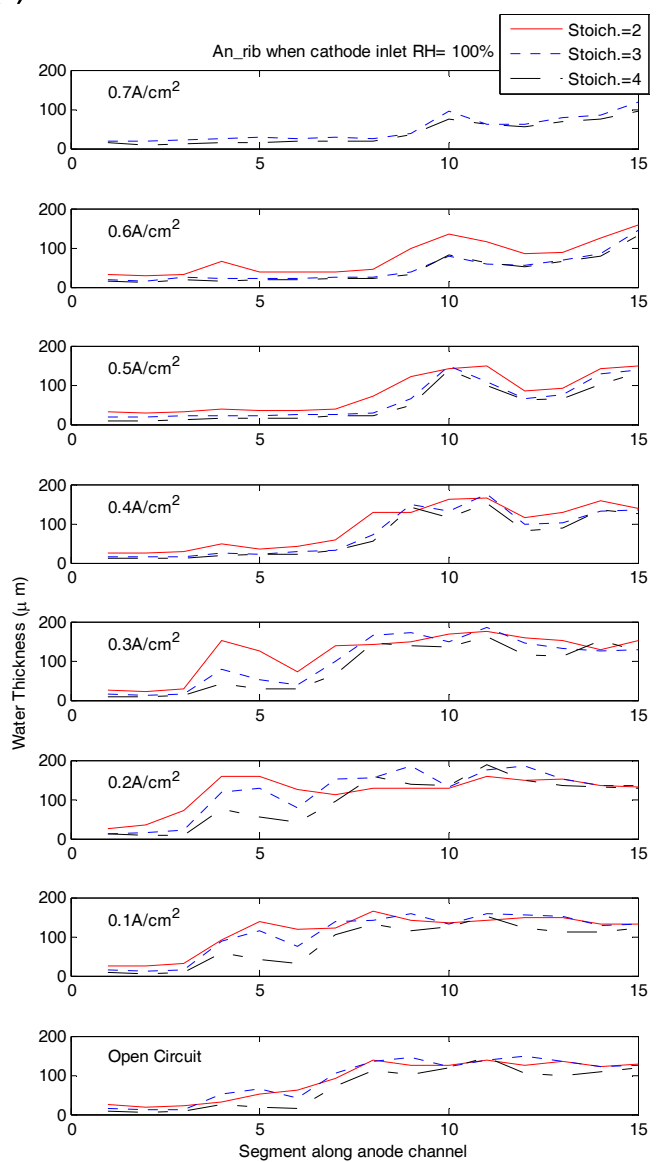

(b)
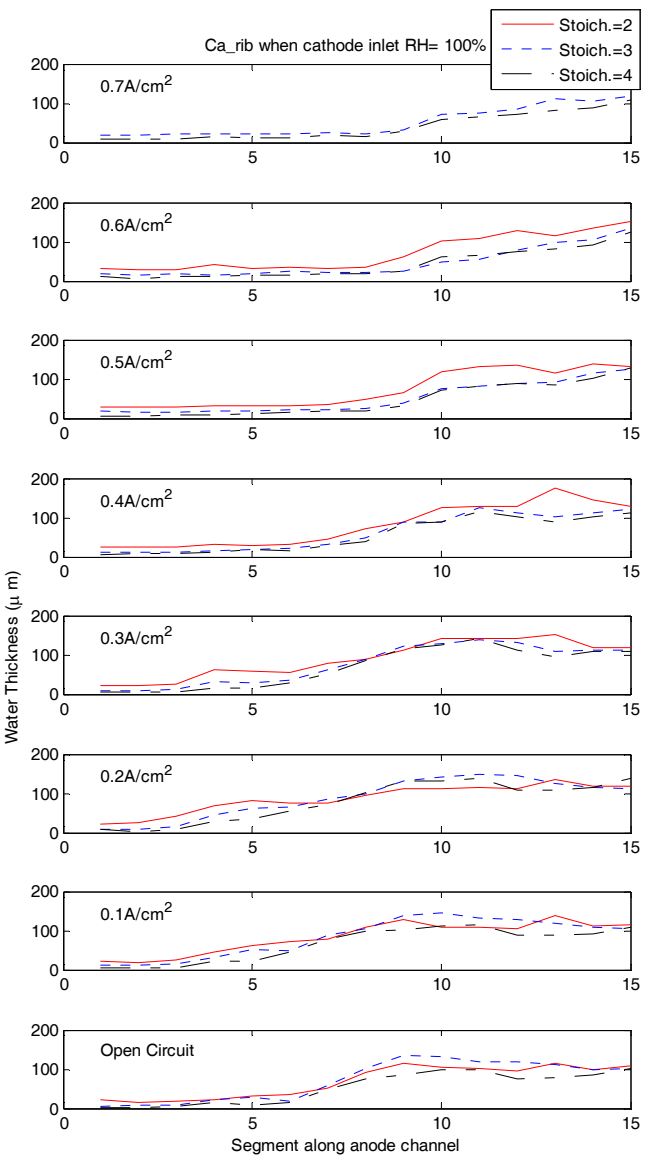

Fig. 10 
Journal of Power Sources, Vol.170, issue 2, July 2007, pp.376-386.
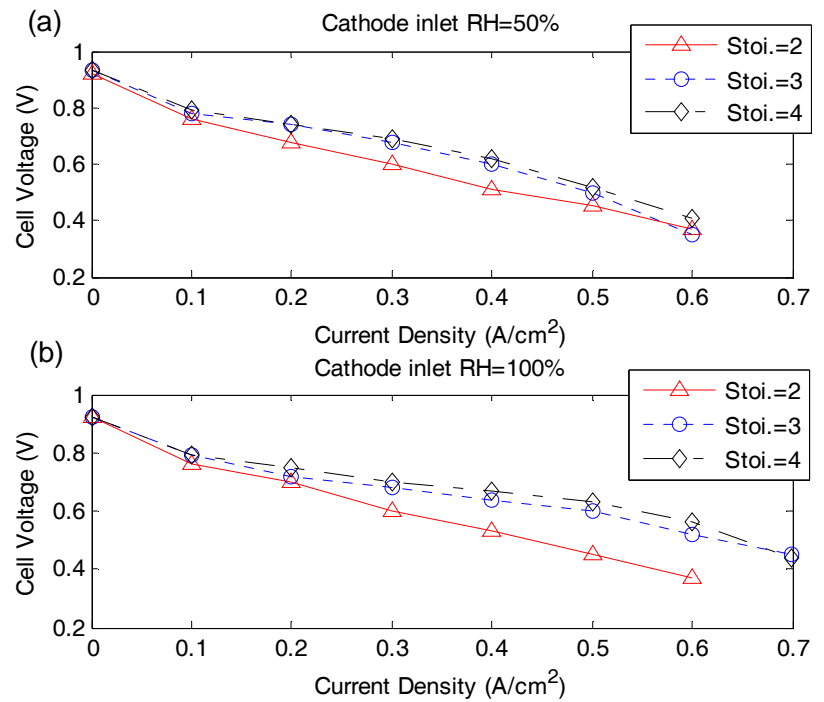

Fig. 11 